\title{
Atorvastatin in the Treatment of Hypercholesterolemia in High Risk Cardiovascular Patients in Bangladesh
}

\author{
MAHTAB H ${ }^{\mathrm{a}}$, MAHMUD RS ${ }^{\mathrm{b}}$, PERVIN K ${ }^{\mathrm{c}}$, SOBHAN MJ
}

\begin{abstract}
Background and aim: This study was to evaluate atorvastatin in the management of hypercholesterolemia of cardiovascular risk patients as well as the implication of National Cholesterol Education Program (NCEP) Adult Treatment Panel (ATP) III guidelines in Bangladesh. Methods: A total 1685 patients aged 28 years or older who had evidence of hypercholesterolemia with or without Coronary Heart Diseases (CHD) and cardiovascular risk factors were assigned to receive atorvastatin for 2 months. The change of fasting $L D L$ at baseline visit and after 2 months of the statin treatment was measured. Results: One thousand six hundred (95\%) patients out of 1685 who were
\end{abstract}

Introduction and Rationale

The sequelae of atherothrombosis, such as coronary heart disease (CHD), cerebrovascular disease and peripheral arterial disease are major causes of morbidity and mortality which ultimately causing premature death. Prevention of these cardiovascular diseases (CVD) requires modification of known risk factors for atherosclerosis such as blood pressure, cholesterol, high profile life style and smoking. ${ }^{1}$ However, these risk factors only partially accounts for the risk of premature CVD and it is very likely that additional factors are of importance. ${ }^{2}$ The interaction of oxidized LDL with arterial wall, endothelial cells, macrophages, vascular smooth muscle cells, platelets and circulating coagulation factors promotes atherosclerosis.,

Hypertriglyceridemia is an independent risk factor of CHD. A recent secondary prevention study of CHD with

a. Prof. Hajera Mahtab, Bangladesh Institute of Health Science

b. Prof. Razia Sultana Mahmud, National Institute of Cardiovascular Diseases

c. Dr. Kumkum Pervin, Dr. Md. Javed Sobhan, Sanofi-Aventis Bangladesh Limited

Address of Correspondence: Prof. Hajera Mahtab, Bangladesh Institute of Health Science, BIHS, Darus Salam, Mirpur, Dhaka

Received: September 10, 2011 Accepted: 22 December, 2011 assigned to receive atorvastatin with $T L C$ were found significant mean reduction $(26.1 \% \downarrow)$ in their LDL levels from baseline visit. Triglycerides and total cholesterols were also reduced $(16.6 \% \downarrow$ and $21.6 \% \downarrow$ respectively) wheras high-density lipoprotein was increased (16.5\% 个) significantly. LDL of $23 \%$ patients was decreased more than $30 \mathrm{mg} / \mathrm{dl}$ after 2 months of atorvastatin treatment. Fifty nine percent of the patients reached the treatment goal of reducing $L D L>20 \mathrm{mg} / \mathrm{dl}$. Conclusion: Atorvastatin would achieve a good effective control in the management of hypercholesterolemic patients with or without $C H D$ and risk factors following the guidelines of US NCEP ATP III.

(Birdem Med J 2012; 2(1): 5-13)

a statin suggested that it may be prudent to target fasting triglycerides (TG) to less than $150 \mathrm{mg} / \mathrm{dl}$. Secondary prevention trials of CHD with drugs acting primarily on TG (fibrates) have shown that reducing TG and increasing high-density lipoprotein (HDL) cholesterol, without significantly affecting LDL slows down coronary artery luminal narrowing (Lopid Coronary Angiography Trial [LOCAT], Bezafibrate Coronary Atherosclerosis Intervention Trial [BECAIT], Bezafibrate Infarction Prevention [BIP]). Statins are also capable of significantly reducing high TG levels. ${ }^{5}$

There are very few studies to investigate the LDL, TG lowering effect of statins in treatment of hypercholesterolemia in Bangladesh. This study is to evaluate atorvastatin in hypercholesterolemic risk patients with inadequate control to diet and exercise as well as the implication of NCEP ATP III guidelines. ${ }^{6}$

Laboratory and experimental evidences suggest that statins can reduce the risk of cardiovascular disease events through modification of blood cholesterol:

Reductions in total and LDL cholesterol achieved with atorvastatin have been shown to translate into reductions in risk of cardiovascular morbidity and mortality in both 
primary and secondary prevention settings. ${ }^{7}$ Significant clinical benefits have specifically been observed among patients with Type 2 diabetes and in those with acute coronary syndromes. ${ }^{8,9}$ In common with other members of the statin class, atorvastatin is well tolerated, and adverse events are generally mild and transient in nature. ${ }^{10,11}$

National Cholesterol Education Program (NCEP) Adult Treatment panel III (ATP III) guidelines and its implication: $6,12.13,14$

Since the publication of Adult Treatment Panel III (ATP III) of the US National Cholesterol Education Program, 5 major clinical trials of statin therapy with clinical end points have been published ${ }^{15,16,17,18,19}$. The trials confirm the benefit of cholesterol-lowering therapy in high-risk patients and support the ATP III treatment goal of low-density lipoprotein cholesterol (LDL) $<100 \mathrm{mg}$ / dl. They support the inclusion of patients with diabetes in the high-risk category and confirm the benefits of LDL lowering therapy in these patients. They further confirm that older persons benefit from therapeutic lowering of LDL.

When LDL-lowering drug therapy is employed in highrisk or moderately high-risk persons, it is advised that intensity of therapy be sufficient to achieve at least a $30 \%$ to $40 \%$ reduction in LDL levels ${ }^{6}$.

\section{The need for atorvastatin evaluation in Bangladeshi patients:}

Following the publication of US NCEP ATP III guidelines five major clinical trials of statin therapy were conducted in countries mostly located in North America, Western Europe and Latin America. The sub-group of patients of Asian origin was too small to be analysed separately. However, there were very few studies to investigate the LDL-lowering effect of statins in the treatment of hypercholesterolemia in Bangladesh.

This study was to evaluate the use of atorvastatin in the management of hypercholesterolemia of cardiovascular risk patients who were inadequately controlled to diet and exercise. Implication of US NCEP ATP III guidelines among the research clinicians was another intention of the study. Another objective was to measure the change of LDL and TG after 2 months of treatment and to assess patients' compliance to atorvastatin treatment.

\section{Subjects and Methods}

Patients:

A total 1685 patients aged 28 years or older who had evidence of hypercholesterolemia with or without Coronary Heart Diseases (CHD) and cardiovascular risk factors as per following criteria were included in the study.

- having CHD* (coronary heart diseases) with LDL$\mathrm{C}>130 \mathrm{mg} / \mathrm{dl} \mathrm{l}^{* *}$. or

- with no $\mathrm{CHD}$ and having $>2$ risk factors $(* * *)$ with LDL-C $>160 \mathrm{mg} / \mathrm{dl} * *$. or

- with no CHD and having $<1$ risk factor $(* * *)$ with LDL- C $>190 \mathrm{mg} / \mathrm{dl} * *$.

\section{Risk factors}

* CHD includes angina pectoris and myocardial infarction.

** Adapted from National Cholesterol Education Program (NCEP) guidelines, ATP III

$* * *$ (a) Elevated total cholesterol levels $(>5.2 \mathrm{mmol} /$ $\mathrm{L}$ or $200 \mathrm{mg} / \mathrm{dl}$ )

(b) Low HDL cholesterol levels $(<1 \mathrm{mmol} / \mathrm{L}$ or $<40 \mathrm{mg} / \mathrm{dl}$ )

(c) Hypertension ( $\mathrm{BP}>140 / 90 \mathrm{mmHg}$ or on antihypertensive medication)

(d) Diabetes mellitus

(e) Family history of premature $\mathrm{CHD}$ (CHD in male first degree relative $<55$ years; $\mathrm{CHD}$ in female first degree relative $<65$ years)

(f) Cigarette Smoking

(g) Obesity (BMI $>30 \mathrm{~kg} / \mathrm{m} 2$ )

(h) Lack of physical exercise

(i) Age $>45$ years for men and $>55$ years for women

\section{Methodology of the study:}

It was a multicentre, open label non comparative study with single group open assessment. Forty centres were involved for enrolling 1685 patients. The study centres were co-coordinated by eight study site coordinators, under the supervision of the Principal Investigator.

The participants were enrolled at these centers in Dhaka city during February 2007 to November 2008. Fasting lipid profiles of the patients were measured at local laboratories with standard procedure. Scheduled study site meetings were held regarding the progress of the 
patients' enrollment and validity of the data in Data Collection Form (DCF). Several levels of data checking were performed: by study site coordinators, monitor, statistician (who did the data management).

The study protocol and DCF were approved by both Regional Medical Affairs of Sanofi-aventis, Singapore, and Global Medical Affairs of Sanofi-aventis, France. Ethical approval was taken from Bangladesh Medical Research Council (BMRC).

\section{Study Endpoints}

The study endpoints were first the number of patients completed the study as per study protocol, number of patients whom fasting LDL and TG were reduced after two month intervention of atorvastatin treatment. There were 1600 patients who had completed the study and their fasting LDL and TG were reduced after 2 months of therapy. No endpoint regarding the efficacy was collected after 2 months of follow up.

\section{Therapeutic intervention:}

Atorvastatin (Orva ${ }^{\circledR}$ ) manufactured by sanofi-aventis Bangladesh was assigned for the patients for their treatment of hypercholesterolemia.

Atorvastatin was prescribed at a dose of 10 to $80 \mathrm{mg}$ daily with or without their other required therapies at the discretion of investigators and research physicians. The dose was adjusted 2 weekly according to the target lipid levels, the recommended goal of therapy and the patient's response.

The treatment duration was 2 months until the final visit at day 60 . Follow up period was 2 months and an interim visits was recommended after one month of treatment. The in-between scheduled visits up to 2 months were arranged according to the requirements.

\section{Results}

General overview and basic demography of the patients:

Out of 1685 enrolled patients, finally 1600 (95\%) completed the study. There were 1042 (65.1\%) male and $558(34.9 \%)$ female patients with age from 28 91 years (54 \pm 11.24$)$, weight $45 \sim 80 \mathrm{Kg}(61.98 \pm 7.89)$, BMI $17.7 \sim 28.8 \mathrm{~kg} / \mathrm{m}^{2}(23.83 \pm 2.53)$. There were no significant mean age difference between male and female $(\mathrm{p}=0.634)$. Male were $1 \mathrm{~kg}$ heavier and BMI was a little more than that of female $(\mathrm{p}<0.001)$.
Majority of the patients; $76.87 \%$ (1230) irrespective of sex were in between the weight group of $50-70 \mathrm{~kg}$ and $81.19 \%$ patients had baseline BMI between $20-27.5$ $\mathrm{kg} / \mathrm{m}^{2}$.

\section{Inclusion criteria of the patients:}

Inclusion criteria were either patient having CHD (angina pectoris/myocardial infarction) + LDL $>130$ $\mathrm{mg} / \mathrm{dl}$ or patient having no $\mathrm{CHD}+>2$ risk factors + $\mathrm{LDL}>160 \mathrm{mg} / \mathrm{dl}$ or patient having no $\mathrm{CHD}+<1$ risk factor + LDL $>190 \mathrm{mg} / \mathrm{dl}$ and lastly patient's ability and willingness to participate in this trial.

More than half (53.6\%) of the patients had CHD with LDL $>130 \mathrm{mg} / \mathrm{dl}$, followed by $38.8 \%$ patient without $\mathrm{CHD}+>2$ risk factors $+\mathrm{LDL}>160 \mathrm{mg} / \mathrm{dl}$. No significant association was noted between sex and inclusion criteria $(\mathrm{p}>0.05)$.

More than half of the patients who were 51 years and above had CHD where $85 \%$ of the patients who were 61 years and above had CHD. On the other hand, more than half of the patients who were 30-50 years old had no CHD but had 2 or more cardiovascular risk factors. Statistically significant association was noted between age and inclusion criteria $(\mathrm{p}<0.05)$. It is understood that young people having risk factors could prevent $\mathrm{CHD}$ in their later age by TLC and clinical management of their risk factors.

\section{Risk factors of the patients:}

The details of all the risk factors were elevated total cholesterol, Low HDL cholesterol, Hypertension, Diabetes mellitus, Family history of premature CHD, Cigarette Smoking, Lack of physical exercise, Age $>$ 45 years for men and $>55$ years for women are shown in Table-I and Table-II according to their sex and age group of the patients respectively. No obesity (BMI > $30 \mathrm{~kg} / \mathrm{m}^{2}$ ) was reported in this study. Most of the patients had multiple risk factors for developing CHD. Among 1042 male patients cumulative 2784 risk factors were recorded, while among 558 female patients 1295 risk factors were noted. Diabetes Mellitus (33.3\% of the cumulative risk factors reported by male and $38.7 \%$ of risk factors of female) and Hypertension ( $27 \%$ of cumulative risk factors of male and $30.7 \%$ of the risk factors of female) were mostly reported risk factors. 
Table I

Distribution of the risk factors of the patients by their sex [Multiple responses Table]

\begin{tabular}{lccc} 
Risk factors & Male & Female & Total \\
\hline Elevated TC level $(>5.2 \mathrm{mmol} / \mathrm{l}$ or $200 \mathrm{mg} / \mathrm{dl})$ & $155(5.6 \%)$ & $85(6.6 \%)$ & 240 \\
Low HDL level $(<1 \mathrm{mmol} / 1$ or $<40 \mathrm{mg} / \mathrm{dl})$ & $124(4.5 \%)$ & $79(6.1 \%)$ & 203 \\
HTN $(\mathrm{BP}>140 / 90 \mathrm{mmHg}$ or on medication) & $752(27.0 \%)$ & $398(30.7 \%)$ & 1150 \\
DM (on diet or OAD/insulin) & $926(33.3 \%)$ & $501(38.7 \%)$ & 1427 \\
Family history of premature CHD & $120(4.3 \%)$ & $93(7.2 \%)$ & 213 \\
Current Cigarette smoking & $468(16.7 \%)$ & 0 & 468 \\
Lack of physical exercise (less than 3 hours/week) & $201(7.2 \%)$ & $126(9.7 \%)$ & 327 \\
Age $>45$ years for men and $>55$ years for women & $38(1.4 \%)$ & $13(1.0 \%)$ & 51 \\
\hline Total & $2784(100 \%)$ & $1295(100 \%)$ & 4079 \\
\hline
\end{tabular}

TC: total cholesterol; HDL: high density lipoprotein; HTN: hypertension; DM: diabetes mellitus;

CHD: coronary heart diseases.

Table II

Distribution of the risk factors of the respondents by age [Multiple responses Table]

\begin{tabular}{lcccccc}
\hline Risk Factors & \multicolumn{5}{c}{ Age group (years) } & Total \\
\cline { 2 - 6 } & $<30$ & $30-40$ & $41-50$ & $51-60$ & $61+$ & \\
\hline Elevated TC & 3 & 41 & 84 & 70 & 42 & $240(5.9 \%)$ \\
Low HDL & 2 & 27 & 54 & 74 & 46 & $203(4.9 \%)$ \\
HTN & 5 & 90 & 399 & 353 & 303 & $1150(28.2 \%)$ \\
DM & 7 & 133 & 492 & 402 & 393 & $1427(35.0 \%)$ \\
Family history of premature CHD & 3 & 6 & 51 & 58 & 95 & $213(5.2 \%)$ \\
Cigarette smoking & 1 & 25 & 114 & 179 & 149 & $468(11.5 \%)$ \\
Lack of physical exercise & 0 & 5 & 73 & 111 & 138 & $327(8.0 \%)$ \\
Age & 0 & 0 & 8 & 5 & 38 & $51(1.3 \%)$ \\
\hline Total & 21 & 327 & 1275 & 1252 & 1204 & $4079(100 \%)$ \\
\hline
\end{tabular}

DM and HTN were reported more than other risk factors in all age groups. DM was reported at a range of $28.1 \%$ $39.1 \%$ among the different age groups, while the range of HTN was $21.7 \%-28.9 \%$. Following DM \& HTN the $3^{\text {rd }}$ highest reported risk factor was smoking. Lack of physical exercise was emerged more as risk factor as the age enhanced. On the other hand risk factors like elevated TC and low HDL were reduced as the age progressed.

\section{Basis of the statin recommendation:}

From the data of 1600 patients participated in the study cumulatively 3938 reasons came out in four categories on the basis of which atorvastatin was recommended. The participating physicians prescribed atorvastatin mainly for its efficacy and safety which contributed 94.8\% and $91.8 \%$ cases respectively. Patient's compliance was another reason for selecting atorvastatin in $59 \%$ cases.

\section{Doses of the atorvastatin:}

Initially mean dose of atorvastatin was $10.81 \pm 2.99$, while after 2 months it was $11.13 \pm 3.34$ (2.96\% \%). The mean difference was statistically significant $(\mathrm{p}<$ 0.05 ). Initially mean target dose was $21.08 \pm 5.07$, while 
after 2 months it was $21.18 \pm 5.15(0.47 \% \uparrow)$. The change in mean regarding target dose was not statistically significant $(\mathrm{p}>0.05)$.

\section{Concomitant therapy:}

During enrolment OAD/Insulin and antihypertensive medications were mostly reported. Four categories of drugs were more used by the patients at end of the study than their enrolment period. Those were antihypertensive $(2.8 \% \uparrow)$, anti anginal $(1.2 \% \uparrow), \mathrm{OAD} /$ Insulin $(1.2 \% \uparrow)$ and other medications of various types $(4.3 \% \uparrow)$. Three drugs were less used than the enrolment period. Those were antithrombotics $(2.1 \% \downarrow)$, antiarrhythmics $(2.9 \% \downarrow)$, and other lipid lowering agents $(0.2 \% \downarrow)$.

\section{General effects of the treatment:}

The changes of patient's weight and BMI after 2 months of the treatment are shown in the Table-III. The mean weight of the patients at the baseline visit was $61.98 \mathrm{~kg}$ and after 2 months it was reduced to $59.84 \mathrm{~kg}(3.45 \%$ $\downarrow)$. The initial mean BMI was $23.83 \mathrm{~kg} / \mathrm{m} 2$ and after 2 months it was reduced to $22.80 \mathrm{~kg} / \mathrm{m} 2(4.3 \% \downarrow)$. Statistically the change in weight and BMI was significant $(\mathrm{p}<0.05)$.

\section{Table-III}

\begin{tabular}{|c|c|c|c|}
\hline \multicolumn{4}{|c|}{ Changes in weight and BMI $(n=1600)$} \\
\hline Weight \& BMI & Mean \pm SD & $\begin{array}{l}\text { Changes in } \\
\text { mean }(\%)\end{array}$ & $\mathrm{p}$ \\
\hline Baseline weight & $61.98 \pm 7.89$ & $3.45 \downarrow$ & $.001(\mathrm{~S})$ \\
\hline $\begin{array}{l}\text { Weight after } \\
2 \text { months }\end{array}$ & $59.84 \pm 6.87$ & & \\
\hline Baseline BMI & $23.83 \pm 2.53$ & $4.3 \downarrow$ & $.001(\mathrm{~S})$ \\
\hline $\begin{array}{l}\text { BMI after } \\
2 \text { months }\end{array}$ & & $22.80 \pm 2.12$ & \\
\hline
\end{tabular}

The initial mean systolic blood pressure (SBP) was $141.04 \mathrm{~mm}$ of $\mathrm{Hg}$ and after 2 months it was reduced to $133.21 \mathrm{~mm}$ of $\mathrm{Hg}(5.6 \% \downarrow)$. Similarly diastolic blood pressure (DBP) was also reduced from $91.73 \mathrm{~mm}$ of $\mathrm{Hg}$ to $85.83 \mathrm{~mm}$ of $\mathrm{Hg}(6.4 \% \downarrow)$ after 2 months. Statistically the change of SBP \& DBP was significant $(\mathrm{p}<0.05)$.

\section{Table IV}

Changes in systolic and diastolic blood pressure

$$
(n=1600)
$$

\begin{tabular}{lccc} 
Blood Pressure & Mean \pm SD & Changes (\%) & $p$ \\
& \multicolumn{3}{c}{ in mean } \\
\hline Baseline SBP & $141.04 \pm 9.14$ & $5.6 \downarrow$ & $.001(\mathrm{~S})$ \\
SBP after 2 months & $133.21 \pm 13.50$ & & \\
Baseline DBP & $91.73 \pm 8.73$ & $6.4 \downarrow$ & $.001(\mathrm{~S})$ \\
DBP after 2 months & $85.83 \pm 4.78$ & & \\
\hline
\end{tabular}

\section{Effects of atorvastatin therapy on serum cholesterols:}

Initial mean of the patients fasting LDL was $191.87 \mathrm{mg} /$ $\mathrm{dl}$ and after 2 months it was decreased to $141.83 \mathrm{mg} / \mathrm{dl}$ $(26.1 \% \downarrow)$ which was statistically significant $(\mathrm{p}<0.05)$. Similarly TG and TC were decreased $16.6 \%$ and 21.6 $\%$ respectively. On the other hand HDL increased 16.5 $\%$ after 2 months of the atorvastatin treatment which was also statistically significant $(\mathrm{p}<0.05)$. Details are shown in the Table-V.

Table-V

Changes in fasting cholesterols level $(n=1600)$

\begin{tabular}{lccc} 
Cholesterols & Mean \pm SD & $\begin{array}{c}\text { Changes in } \\
\text { mean (\%) }\end{array}$ & $\mathrm{p}$ \\
\hline Baseline LDL & $191.87 \pm 31.45$ & $26.1 \downarrow$ & $.002(\mathrm{~S})$ \\
LDL after 2 months & $141.83 \pm 28.96$ & & \\
Baseline HDL & $41.75 \pm 8.73$ & $16.5 \downarrow$ & $.003(\mathrm{~S})$ \\
HDL after 2 months & $48.65 \pm 8.83$ & & \\
Baseline TG & $209.86 \pm 41.75$ & $16.6 \downarrow$ & $.001(\mathrm{~S})$ \\
TG after 2 months & $174.93 \pm 30.51$ & & \\
Baseline TC & $282.23 \pm 37.03$ & $21.6 \downarrow$ & $.002(\mathrm{~S})$ \\
TC after 2 months & $221.29 \pm 36.48$ & & \\
\hline
\end{tabular}

LDL of $23 \%$ patients ( $24.2 \%$ male \& $20.7 \%$ female) was decreased more than $30 \mathrm{mg} / \mathrm{dl}$ after 2 months of atorvastatin treatment. Around $59 \%$ of the patients reached the treatment goal of reducing $\mathrm{LDL}>20 \mathrm{mg} / \mathrm{dl}$ as shown in the Table-VI. 


\section{Table-VI}

\begin{tabular}{lcccccc}
\multicolumn{7}{c}{ Changes of LDL-C in $m g / d l(n=1600)$} \\
\multicolumn{5}{c}{ Changes of fasting LDL-C $(\mathrm{mg} / \mathrm{dl})$} \\
\cline { 2 - 6 } & $<10$ & $10.01-20$ & $20.01-30$ & $30.01-40$ & $41+$ & Total \\
\hline Male & $180(17.3 \%)$ & $244(23.4 \%)$ & $366(35.1 \%)$ & $171(16.4 \%)$ & $81(7.8 \%)$ & 1042 \\
Female & $104(18.6 \%)$ & $140(25.1 \%)$ & $198(35.5 \%)$ & $89(15.9 \%)$ & $27(4.8 \%)$ & 558 \\
Both & $284(17.7 \%)$ & $384(24.0 \%)$ & $564(35.3 \%)$ & $260(16.3 \%)$ & $108(6.7 \%)$ & 1600 \\
\hline
\end{tabular}

Table VII

\begin{tabular}{lcccccc}
\multicolumn{7}{c}{ Changes in LDL-C according to age $(n=1600)$} \\
Age (Yrs) & $<10$ & $10.01-20$ & $20.01-30$ & $30.01-40$ & $41+$ & Total \\
\cline { 2 - 6 } & $1(16.7 \%)$ & 0 & $1(16.7 \%)$ & $2(33.3 \%)$ & $2(33.3 \%)$ & 6 \\
$30-40$ & $19(13.1 \%)$ & $32(22.1 \%)$ & $48(33.1 \%)$ & $33(22.8 \%)$ & $13(9.0 \%)$ & 145 \\
$41-50$ & $102(18.1 \%)$ & $127(22.5 \%)$ & $206(36.5 \%)$ & $83(14.7 \%)$ & $46(8.2 \%)$ & 564 \\
$51-60$ & $72(15.6 \%)$ & $118(25.5 \%)$ & $171(37.0 \%)$ & $76(16.5 \%)$ & $25(5.4 \%)$ & 462 \\
$61+$ & $90(21.3 \%)$ & $107(25.3 \%)$ & $138(32.6 \%)$ & $66(15.6 \%)$ & $22(5.2 \%)$ & 423 \\
\hline
\end{tabular}

Chi - Square 28.707 $\mathrm{p}=0.026$

LDL was decreased more than $30 \mathrm{mg} / \mathrm{dl}$ after 2 months of atorvastatin treatment in $31.8 \%$ patient age between $30-40$ years, $22.9 \%$ patient age between $41-$ 50 years, $21.9 \%$ of patients age between $51-60$ years and $20.8 \%$ patient age 61 years and older as shown in the Table-VII. Statistically significant association was noted between changes in LDL and age groups $(\mathrm{p}<0.05)$.

\section{Adverse drug reaction, tolerance and reported effectiveness of atorvastatin:}

All doses of atorvastatin were well tolerated. Thirty patients $(1.9 \%)$ reported at least one treatment-emergent adverse event. The majority of treatment-emergent adverse events were mild and considered unrelated to atorvastatin treatment; the most common being headache, myalgia, nausea, back pain. No discontinuation of study drug due to adverse event was reported. There were no serious adverse events reported. Effectiveness of atorvastatin was reported among $98.1 \%$ cases. $98.4 \%$ cases stated that prescribed atorvastatin was tolerable. LDL goal ( $30 \%$ of target) was achieved in $98.1 \%$ cases as reported by physicians.

\section{Compliance and assessment of atorvastatin treatment:}

In $45.3 \%$ cases patients' compliance was reported as very good and in $53.5 \%$ was good. In $38.3 \%$ cases physician's overall assessment regarding use of atorvastatin was very good and 57\% physician' opinion was good. More than $97 \%$ cases patient's overall assessment on the treatment was good.

\section{Discussion}

The purpose of this open label non comparative study was to evaluate the use of atorvastatin in hypercholesterolemia of cardiovascular risk patients who were inadequately control to diet and exercise. Implication of US NCEP ATP III guidelines among the research clinicians was another intention of the study.

In this study population with mean age 54 years Body mass index (BMI) was lower compared to Western population ( $24 \pm 3$ vs $28 \pm 4$ ). Hypertensive patients and cigarette smokers were more in this study compare to other study with high risk cardiovascular patients (e.g. The HOPE study) ${ }^{20}$. Recent epidemiologic survey in 
Bangladesh showed that hypertension and diabetes are high prevalence in the population. The incidence of high cholesterol level is still lower than that in the western countries.

More than half of the patients who were 51 years and above had CHD where $85 \%$ of the patients who were 61 years and above had CHD. Most of the patients had multiple risk factors for developing CHD. Diabetes Mellitus and Hypertension were mostly reported risk factors. Following DM \& HTN the $3^{\text {rd }}$ highest reported risk factor was smoking. Lack of physical exercise was emerged more as risk factor as the age enhanced. Conversely, risk factors like elevated TC and low HDL were reduced as the age progressed. No obesity (BMI $>30 \mathrm{~kg} / \mathrm{m}^{2}$ ) was reported in this study.

The study physicians prescribed atorvastatin mainly for its efficacy and safety which contributed $94.8 \%$ and 91.8\% cases respectively. Patient's compliance was another reason for selecting atorvastatin in 59\% cases. Atorvastatin was prescribed with or without their other required therapies at the discretion of investigators and research physicians. The recommended commencing dose for atorvastatin was $10 \mathrm{mg}$ per day and highest recommended dose was $80 \mathrm{mg} /$ day. The dose was adjusted 2 weekly according to the target lipid levels, the recommended goal of therapy and the patient's response. The concomitant treatment was to control other risk factors and was adjusted at the discretion of the physicians.

The mean weight of the patients at the baseline visit was $61.98 \mathrm{~kg}$ and after 2 months it was reduced to 59.84 $\mathrm{kg}(3.45 \% \downarrow)$. The initial mean BMI was $23.83 \mathrm{~kg} / \mathrm{m} 2$ and after 2 months it was reduced to $22.80 \mathrm{~kg} / \mathrm{m} 2(4.3$ $\% \downarrow)$. Statistically the change in weight and BMI was significant $(\mathrm{p}<0.05)$. The initial mean systolic blood pressure (SBP) was $141.04 \mathrm{~mm}$ of $\mathrm{Hg}$ and after 2 months it was reduced to $133.21 \mathrm{~mm}$ of $\mathrm{Hg}(5.6 \% \downarrow)$. Similarly diastolic blood pressure (DBP) was also reduced from $91.73 \mathrm{~mm}$ of $\mathrm{Hg}$ to $85.83 \mathrm{~mm}$ of $\mathrm{Hg}(6.4 \% \downarrow)$ after 2 months. Statistically the change of SBP \& DBP was significant $(\mathrm{p}<0.05)$. Initial mean of the patients fasting LDL was $191.87 \mathrm{mg} / \mathrm{dl}$ and after 2 months it was decreased to $141.83 \mathrm{mg} / \mathrm{dl}(26.1 \% \downarrow)$ which was statistically significant $(\mathrm{p}<0.05)$. Similarly TG and TC were decreased $16.6 \%$ and $21.6 \%$ respectively. On the other hand HDL increased $16.5 \%$ after 2 months of the atorvastatin treatment which was also statistically significant $(\mathrm{p}<0.05)$. LDL of $23 \%$ patients $(24.2 \%$ male \& $20.7 \%$ female) was decreased more than $30 \mathrm{mg} / \mathrm{dl}$ after 2 months of atorvastatin treatment.

According to the study design, the diagnosis and the management of adverse events as well as the discontinuation of atorvastatin during follow-up period were authorized to the physicians. Altogether there were 30 individuals who had some forms of adverse event but no discontinuation of study drug was reported. No serious adverse event was reported in this study.

About 98\% cases physician reported the drug was effective and in $98.4 \%$ cases the drug was tolerable to the participants. Patient's compliance to the atorvastatin treatment was found good in around $98 \%$ cases where more than $97 \%$ cases patient's overall assessment of the treatment was good. Physician's overall assessment was good in more than $95 \%$ cases.

The result of cholesterols lowering effect of atorvastatin and patient's compliance to the treatment in this study is encouraging. Though the follow up period was only two months in this study it shows that hypercholesterolemic patients with risk factors of CHD could get good therapeutic effect from atorvastatin when the clinical management comply with ATP III of the US NCEP guidelines.

\section{Conclusion}

One thousand six hundred (1600) patients finally completed the study according to the protocol. Around $59 \%$ of the patients reached the treatment goal of reducing LDL $>20 \mathrm{mg} / \mathrm{dl}$. After 2 months of atorvastatin therapy with TLC significant reduction in LDL (26.1\% $\downarrow)$ TG $(16.6 \% \downarrow)$ and total cholesterols $(21.6 \% \downarrow)$ levels were reported where high-density lipoprotein was increased $(16.5 \% \downarrow)$ significantly from the baseline level. The incidence of adverse events was low (2\%) and could not be found dose dependent. Overall patients' compliance of the statin therapy was good.

The result demonstrates that study drug atorvastatin is effective, safe and tolerable to Bangladeshi hypercholesterolemic patients with CHD risk factors. To achieve the full therapeutic result of the atorvastatin with good effective treatment compliance the clinical management should comply with the US NCEP ATP III guidelines. 


\section{Acknowledgement}

The study was funded by an unrestricted educational grant of sanofi-aventis Bangladesh Limited. We specially thank all the study investigators and the study report reviewer Dr. Kamrun Nahar Choudhury, National Centre for Control of Rheumatic Fever and Heart Diseases for hard work and commitment.

\section{References}

1. Martin MJ, Hulley SB, Brown WS, et al. Serum cholesterol, blood pressure and mortality: implications from a cohort of 361, 662 men. Lancet 1986; ii: 933-36.

2. Keys A. Seven countries: a multivariate analysis of health and coronary heart disease. Harvard University Press. 1980.

3. Steinberg D, Parthasarathy S, Carew TE, et al. Beyond cholesterol. Modifications of low-density lipoprotein that increase its atherogenicity. N Engl J Med 1989; 320: 915-24.

4. Berry EM. The effects of nutrients on lipoprotein susceptibility to oxidization. Current Opinion Lipidology 1992; 3:5-11.

5. Patrick Duriez, Jean-Charles Fruchart, Recent Developments in the Treatment of Hypertriglyceridemia, Current Atherosclerosis Reports 1999, 1:31-37.

6. Scott M. Grundy; James I. Cleeman; C. Noel Bairey Merz; H. Bryan Brewer, Jr; Luther T. Clark; Donald B. Hunninghake, Implications of Recent Clinical Trials for the National Cholesterol Education Program Adult Treatment Panel III Guidelines, Circulation. 2004; 110:227-39.

7. Sander I van Leuven, -John JP Kastelein, Atorvastatin: Expert Opinion on Pharmacotherapy, Academic Medical Center of Amsterdam, June 2005, Vol. 6, No. 7, Pages 1191-1203.

8. Sever PS, Dahlof B, Poulter NR, Wedel H, Beevers G, Caulfield M, et al; ASCOT investigators. Prevention of coronary and stroke events with atorvastatin in hypertensive patients who have average or lower-than-average cholesterol concentrations, in the Anglo-Scandinavian Cardiac Outcomes Trial- Lipid Lowering Arm (ASCOT-LLA): a multicentre randomised controlled trial. Lancet. 2003;361:1149-58.

9. Cannon CP, Braunwald E, McCabe CH, Rader DJ, Rouleau JL, Belder R, et al; Pravastatin or Atorvastatin Evaluation and Infection Therapy-Thrombolysis in Myocardial Infarction 22 Investigators. Intensive versus moderate lipid lowering with statins after acute coronary syndromes. N Engl J Med. 2004;350:1495-1504.

10. Jones PH, Davidson MH, Stein EA, Bays HE, McKenney JM, Miller E, Cain VA, et al; STELLAR Study Group. Comparison of the efficacy and safety of rosuvastatin versus atorvastatin, simvastatin, and pravastatin across doses (STELLAR* Trial). Am J Cardiol. 2003; 92: 152-60.

11. Jones P, Kafonek S, Laurora I, Hunninghake D. Comparative dose efficacy study of atorvastatin versus simvastatin, pravastatin, lovastatin, and fluvastatin in patients with hypercholesterolemia (the CURVES study). Am J Cardiol. 1998;81:582-87.

12. National Cholesterol Education Program (NCEP) Expert Panel on Detection, Evaluation, and Treatment of High Blood Cholesterol in Adults (Adult Treatment Panel III). Third Report of the National Cholesterol Education Program (NCEP) Expert Panel on Detection, Evaluation, and Treatment of High Blood Cholesterol in Adults (Adult Treatment Panel III) final report. Circulation. 2002;106:3143-3421.

13. Expert Panel on Detection, Evaluation, and Treatment of High Blood Cholesterol in Adults. Executive Summary of the Third Report of the National Cholesterol Education Program (NCEP) Expert Panel on Detection, Evaluation, and Treatment of High Blood Cholesterol in Adults (Adult Treatment Panel III). JAMA. 2001; 285:2486-97.

14. National Cholesterol Education Program. Second Report of the Expert Panel on Detection, Evaluation, and Treatment of High Blood Cholesterol in Adults (Adult Treatment Panel II). Circulation. 1994; 89:1333-45.

15. Nissen SE, Tuzcu EM, Schoenhagen P, Brown BG, Ganz P, Vogel RA, et al; REVERSAL Investigators. Effect of intensive compared with moderate lipid-lowering therapy on progression of coronary atherosclerosis: a randomized controlled trial. JAMA. 2004; 291:1071-80.

16. Waters DD, Guyton JR, Herrington DM, McGowan MP, Wenger NK, Shear C; TNT Steering Committee Members and Investigators. Treating to New Targets (TNT) Study: does lowering low-density lipoprotein cholesterol levels below currently recommended guidelines yield incremental clinical benefit? Am J Cardiol. 2004; 93:154-58.

17. Ballantyne CM, Houri J, Notarbartolo A, Melani L, Lipka LJ, Suresh R, et al; Ezetimibe Study Group. Effect of ezetimibe co-administered with atorvastatin in 628 patients with primary hypercholesterolemia: a prospective, randomized, doubleblind trial. Circulation. 2003; 107:2409-15.

18. Jenkins DJ, Kendall CW, Marchie A, Faulkner DA, Wong JM, de Souza R, et al. Effects of a dietary portfolio of cholesterol lowering foods vs lovastatin on serum lipids and C-reactive protein. JAMA. 2003; 290:502-10.

19. Bays HE, Dujovne CA, McGovern ME, White TE, Kashyap ML, Hutcheson AG, et al; ADvicor Versus Other CholesterolModulating Agents Trial Evaluation. Comparison of oncedaily, niacin extended-release/lovastatin with standard doses of atorvastatin and simvastatin (the ADvicor Versus Other Cholesterol-Modulating Agents Trial Evaluation [ADVOCATE]). Am J Cardiol. 2003; 91:667-72.

20. The heart outcomes prevention evaluation study investigators. Effects of an angiotensin- converting enzyme inhibitor, ramipril, on cardiovascular events in high-risk patients. N Engl J Med 2000;342:145-53. 
21. Dean BB, Borenstein JE, Henning JM, Knight K, Bairey Merz CN. Can change in HDL-cholesterol reduce cardiovascular risk? Am Heart J. 2004; 147:966-76.

22. Rubins HB. Triglycerides and coronary heart disease: implications of recent clinical trials. J Cardiovasc Risk. 2000; 7:339-45.

23. Law MR, Wald NJ, RudnickaAR. Quantifying effect of statins on low density lipoprotein cholesterol, ischaemic heart disease, and stroke: systematic review and meta-analysis. BMJ. 2003; 326:1423.
24. Davidson MH, McGarry T, Bettis R, Melani L, Lipka LJ, LeBeaut AP, et al. Ezetimibe co-administered with simvastatin in patients with primary hypercholesterolemia. J Am Coll Cardiol. 2002; 40: 2125-34.

25. Rubins HB, Robins SJ, Collins D, Fye CL, Anderson JW, Elam MB, et al. Gemfibrozil for the secondary prevention of coronary heart disease in men with low levels of high-density lipoprotein cholesterol. Veterans Affairs High- Density Lipoprotein Cholesterol Intervention Trial Study Group. N Engl J Med. 1999;341:410-18. 